\title{
LETTERS
}

Send your letters to the editor, British Dental Journal, 64 Wimpole Street, London W1G 8YS or by email to bdj@bda.org

Priority will be given to letters less than 500 words long. Letters should be typed. Authors must sign the letter, which may be edited for reasons of space

\section{Curry leaves}

Sir, it is nice to know that dental decay in children's teeth is decreasing in the UK as reported recently in the BDJ's news pages (BDJ 2004, 197:64)

In developing countries, (more often in the rural areas) there is higher prevalence of dental and periodontal disease due to negligence and lack of awareness and the cost of oral health care has increased in these countries.

Essential oil (E0) mouthwashes are important in oral health management ${ }^{1}$. They contain thymol, eucalyptus oil and menthol and the tepenes present have antibacterial and antifungal activity ${ }^{2,3}$. They have broad antimicrobial effects, are microbiologically safe ${ }^{3,4}$ and have the ability to penetrate the plaque biofilm killing the microorganisms ${ }^{5}$.

The curry leaf tree (Murraya Koenigii spreng - a green leafy vegetable) is grown all over India and other countries for its aromatic leaves which are used daily as an ingredient in Indian cuisine.

The fresh curry leaves contain 2.6\% volatile essential oils (containing sesquiterpenes and monoterpenes) ${ }^{6}$ and the essential oils in the curry leaves are sufficiently soluble in water.

They contain $21000 \mu \mathrm{g}$ total carotene, $7100 \mu \mathrm{g}$ beta carotene, $93.9 \mu \mathrm{g}$ total folic acid, $0.21 \mathrm{mg}$ riboflavin, $0.93 \mathrm{mg}$ iron, $830 \mathrm{mg}$ calcium, $57 \mathrm{mg}$ phosphorus and $0.20 \mathrm{mg}$ zinc per $100 \mathrm{~g}^{7}$.

The cold extract of curry leaves ( $10 \mathrm{~g}$ of cut fresh curry leaves in $200 \mathrm{ml}$ of distilled water) has a $\mathrm{pH}$ of 6.3 to 6.4. (unpublished personal observations). Chlorophyll has been proposed as an anticariogenic agent and it also helps to reduce halitosis ${ }^{8}$.

We have observed that holding curry leaves in the mouth for 5 to 7 minutes is helpful in reducing halitosis ${ }^{9}$ and that the terpenes have been found to reduce airborne chemicals and bacteria ${ }^{10}$.

In addition to the presence of EO, the curry leaves contain chlorophyll, beta carotene and folic acid, riboflavin, calcium and zinc and all these can act on the oral tissues and help in keeping up good oral health. Chewing 2 to 4 fresh

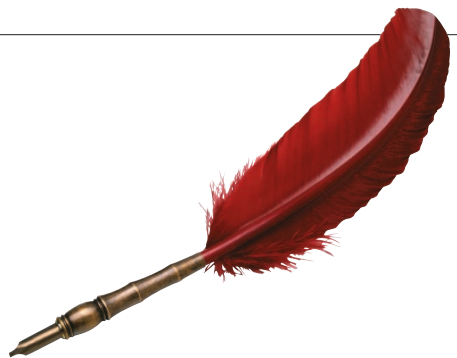

curry leaves with 10 to $15 \mathrm{mls}$ water in the mouth, swishing for 5 to 7 minutes and rinsing the mouth out with water can be of help in keeping good oral hygiene and as the curry leaf is a green leafy vegetable it will be safe and cheap to use as

mouthwash.

M. V. Math

\section{P. Balasubramaniam}

\section{Mumbai}

doi: 10.1038/sj.bdj.4811838

1. Claffey N. Essential oil mouthwash : a key component in oral health management. J Clin Periodontol. 2003; 30 (suppl. 5): 22-24.

2. Dolara P, Corte B, Ghelardini C, et al. Local anaesthetic, antibacterial and antifungal properties of sesquiterpenes from myrrh. Planta Med 2000; 66: 356-8

3. Bernimoulin JP. Recent concepts in plaque formation. J Clin Periodontol. 2003; 30 (suppl. 5) : 7-9

4. Santos A. Evidence based control of plaque and gingivitis J Clin Periodontol. 2003; 30 (suppl. 5) : 1316

5. Ouhayoun JP. Penetrating the plaque biofilm : impact of essential oil mouthwash. J Clin Periodontol. 2003; 30 (suppl. 5): 10-12

6. Indian Institute of Spice Research (www.iisr.org/spices/curryleaves.htm)

7. Gopalan C, Rama sastri BV, Balasubramanian SC. In Nutritive Value of Indian Foods, revised and updated Narasinga rao BS, Deosthale YG, Pant KC. National Institute of Nutrition ICMR Hyderabad, India. 2000.

8. Shafer WG, Hine MK, Levy BM, Tomich CE. Dental caries. A Text Book of Oral Pathology. pp254-262 New Delhi, Saunders, 2002.

9. Math MV and Balasubramaniam P. Curry leaves (Murraya Koenigii spreng) and halitosis. BMJSouth Asia edition 2003;19(3):211

10. Odorchem Manufacturing Corp. Canada (ww.air8solutions.com)

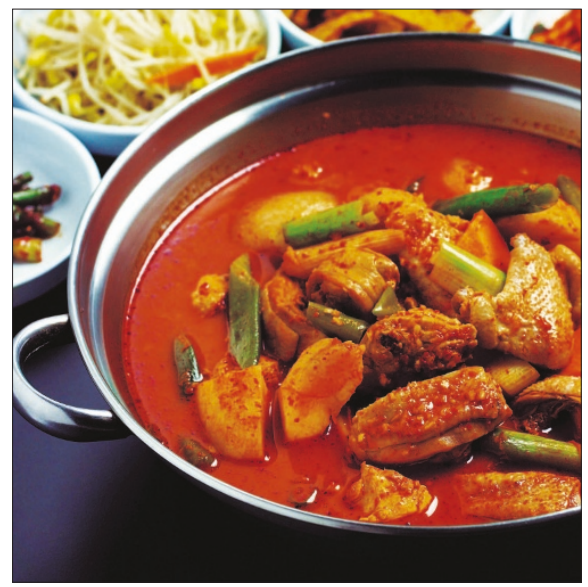

Curry leaves are often used in Indian cuisine 


\section{LETTERS}

\section{Sugar-sweetened drinks}

Dentists often advise patients against the frequent consumption of carbonated drinks and fruit juices because of the potential cariogenic risk and association with tooth wear.

The results of recent research also suggest that such dietary habits may also be linked with wider health problems. For example, Ludwig et al. (2001) ${ }^{1}$ found that the risk of becoming obese in childhood was increased 1.6 fold for every sugarsweetened drink consumed per day.

This is not surprising when one considers that a 12-oz can of sugar sweetened drink may contain between 40 50 grams of sugar.

A recent study published in the Journal of the American Medical Association has reported a link between the consumption of sugar-sweetened beverages, weight gain and the incidence of type II diabetes in young and middle-aged women. ${ }^{2}$

This prospective questionnaire based cohort study followed up over 50,000 American nurses between 1991 and 1999. Weight gain over a four year period was highest among women who increased their sugar-sweetened soft drink consumption to one or more drinks per day (multi-variate adjusted means, 4.69 $\mathrm{kg}$ for 1991 to 1995 and $4.2 \mathrm{~kg}$ for 1995 to 1999) after adjusting for lifestyle and dietary confounders.

Also following adjustment for confounders, women consuming one or more sugar-sweetened soft drinks per day had a relative risk of type II diabetes of 1.83 (95\% confidence interval 1.42-2.36; $\mathrm{P}<0.001)$ compared to those who

\section{Rotation of wisdom}

\section{teeth}

Sir, a 19-year-old female patient was referred to our department by her general dental surgeon for the removal of her lower wisdom teeth.

At her appointment for the removal of the first wisdom tooth, the orthopantomogram (Figure 1), which was taken 18 months previously, was noted to be different compared with the newer one (Figure 2).

The wisdom teeth seem to have rotated and changed their position from mesioangulated to horizontal. Y. Zanganah

\section{A. Yousefpour}

T. Hall Worcestershire doi: 10.1038/sj.bdj.4811842 consumed less than one of these

beverages per month. Interestingly, fruit juice and diet-drink consumption was not associated with diabetes risk.

The increased risk of diabetes with sugar-containing soft drinks maybe because they induce rapid increases in blood glucose and insulin concentration. In giving dietary advice, dentists should counsel patients about the wider health effects of high sugar-sweetened soft drink consumption as well as the dental effects.

Soft drink machines placed in public places should contain healthier options and the food industry should be encouraged to reduce the sugar content of products.

S. K. Gill

D. S. Gill

\section{London}

doi: $10.1038 /$ sj.bdj.4811839

1. Ludwig DS, Peterson KE, Gortmaker SL. Relation between consumption of sugar-sweetened drinks and childhood obesity: a prospective, observational analysis. Lancet 2001; 357: 505-508.

2. Schulze MB, Manson JE, Ludwig DS et al. SugarSweetened Beverages, Weight Gain, and Incidence of Type 2 Diabetes in Young and Middle-Aged Women. JAMA 2004: 292: 927-934.

\section{Dental understanding}

Sir, if

a. dento-alveolar surgery is the domain of the surgical dentist/oral surgeon; b. the claim of the oculoplastic surgeon to treat the orbit and fractured zygomatic bones as they are best able to repair/adjust the extra-ocular musculature is accepted; c. head and neck tumour work is the legitimate work for ENT, plastic as well as other surgical specialities;

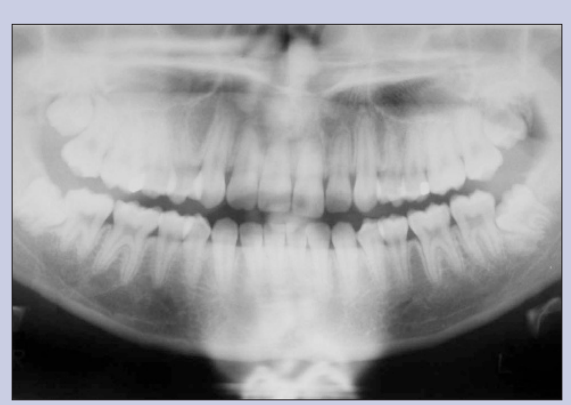

Figure 1

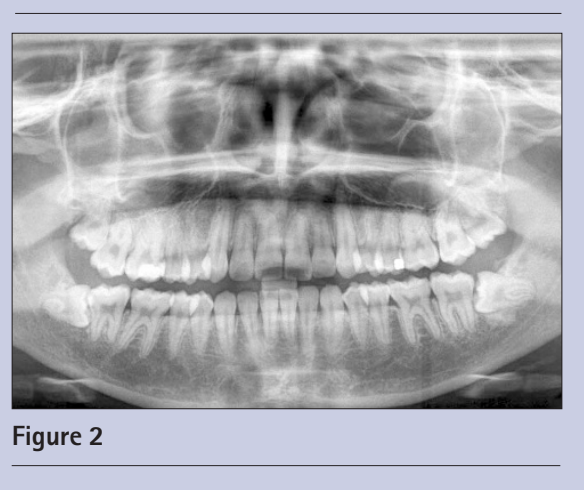

d. the Government requirement for hospital based general anaesthetics for exodontia is to remain as currently undertaken by the Community Service; And e. fracture treatment of the mandible is to remain as hand holding the fractured bone ends for plating with the final occlusal discrepancies being adjusted by tooth grinding rather than establishing the correct occlusion.

Thus no dental understanding is required. What is the remit or need for the future oral and maxillofacial surgeon?

It seems pointless to discuss training when clearly there is likely to be no need for us when others apparently can equally well undertake the work.

The surgically trained dentist will always be needed in our district hospitals. The British Association of Oral Surgeons no doubt will argue this point and build on such a needed district based service.

Does this have a ring of deja vu?

\section{G. D. Wood}

By email

doi: 10.1038/sj.bdj.4811840

\section{Rofecoxib and dental prescribing}

Sir, general dental practitioners are currently being sent the British National Formulary (BNF) Number 48, which replaces the Dental Practitioners'

Formulary 2002-2004.

On reading the BNF they will be aware that there have been additions to the Dental Practitioners' list i.e. medications that can be prescribed on form FP10D (GP14 in Scotland, WP10D in Wales) for NHS patients.

These additions are principally various artificial saliva substitutes and the analgesic Rofecoxib, a cyclo-oxygenase-2 (COX-2 selective) non-steroidal antiinflammatory drug (NSAID).

Dental practitioners however may not be aware that since the BNF was printed, new research has shown that Rofecoxib increases the risk of myocardial infarction and stroke if taken for long periods.

As a consequence Rofecoxib has now been voluntarily withdrawn from the worldwide market by its pharmaceutical manufacturer and is no longer available for prescription ${ }^{1}$.

M. N. Pemberton

Manchester

doi: $10.1038 /$ sj.bdj.4811841

1. Singh $D$, Merck withdraws arthritis drug world wide BMJ 2004; 329:816. 